\title{
Developing an Educational Design Pattern Language for MOOCs
}

\author{
Aracele Garcia de Oliveira Fassbinder ${ }^{1,2}$, Ellen Francine Barbosa ${ }^{2}$, George D. Magoulas $^{3}$ \\ ${ }^{1}$ Federal Institute of Education, Science and Technology of South of Minas Gerais \\ (IFSULDEMINAS), Muzambinho, Minas Gerais, Brazil. \\ ${ }^{2}$ Institute of Mathematical and Computer Sciences (ICMC), University of São Paulo (USP), \\ São Carlos, São Paulo, Brazil. \\ ${ }^{3}$ Knowledge Lab, Birkbeck College, University of London, United Kingdom. \\ aracele.garciadifsuldeminas.edu.br, francinedicmc.usp.br, \\ gmagoulasedcs.bbk.ac.uk
}

\begin{abstract}
The paper advocates a course design approach based on learning design patterns and introduces a pattern language to support design for learning in Massive Open Online Courses (MOOCs). The current version of the Educational Design Pattern Language contains thirty-nine patterns organized into eight categories. Furthermore, it is guided by the Flipped Learning Teaching Model as a pedagogical approach. The paper discusses theoretical and practical aspects of the pattern language, its development, validation, and usefulness for educators and technologists. The application of the approach is illustrated with a case study in the area of Software Engineering education.
\end{abstract}

\section{Context}

Design Patterns and Pattern Languages have received much attention in several areas due to their potential to act as a simple way to describe and share tacit knowledge and support new product development with notable applications in architectural design (Alexander et al.,1977) and software development (Gamma et al.,1995).

In this paper, we explore the potential of Design Patterns and Pattern Languages in the learning design context, as a strategy to collect and formalize practitioners' experiences and evidence from empirical activities to enhance the development of open and online courses. In particular, we focus on Massive Open Online Courses, generally referred as MOOCs (Siemens, 2013), which provide opportunities for socialization, collaboration, professional training, and lifelong learning support.

There is a rapidly growing interest of institutions and educators in designing and delivering MOOCs either using popular providers, such as Coursera (coursera.org), MiríadaX (miriadax.net), edX (edx.org), and Future Learn (futurelearn.com), or adapting open platforms to their own infrastructure, such as Google Course Builder (edu.google.com/openonline), open edX (open.edx.org), and the Brazilian instance named Tim Tec (timtec.com.br/pt/funcionalidades). Although MOOCs have a lot of potentials, most of the existing courses are still based on traditional classroom formats, which are less effective as a means of learning in this context (Fassbinder, Delamaro, and Barbosa, 2014). Furthermore, they are not designed in a way that encourages personalized and self-regulated learning, which also contributes to high dropout rates.

This challenging situation has stimulated the development of patterns-based approaches to support educators when designing innovative learning experiences in MOOCs (Warburton and Mor, 2015). However, according to previous studies (Fassbinder, Delamaro, and Barbosa, 2014; Fassbinder et al., 2017b), current approaches face some limitations. They do not focus on the entire design process, and 
MOOC teams are still using ad hoc decision-making procedures, institutional or MOOC providers' guidelines to design for learning.

In this context, this paper aims at investigating how an educational design pattern language and its related patterns can be used as an effective way of connecting research findings with design and development practices and thus can act as a guide to support learning designers and educators to enhance students' experiences in MOOCs. Findings from this work may also have implications for the activity of educational technologists, especially those involved with the development of MOOC platforms.

The paper is organized as follows: Section 2 provides an overview of the Pattern Language (PL) development method. The PL itself is presented in Section 3, while its application is exemplified through a case study on Agile Software Development in Section 4. The PL evaluation methods are described in Section 5 and discussed in Section 6. Conclusions and insights for future research and practice are presented in Section 7.

\section{The Educational Design Pattern Language development method}

Our approach for the PL development is a mixture of procedures defined by Braga, Ré, and Masiero (2007) and Iba, Sakamoto, and Miyake (2011), incorporating seven main phases as summarized in Fig. 1. Although the PL development method appears to be sequential, it is based on an iterative and incremental flow.

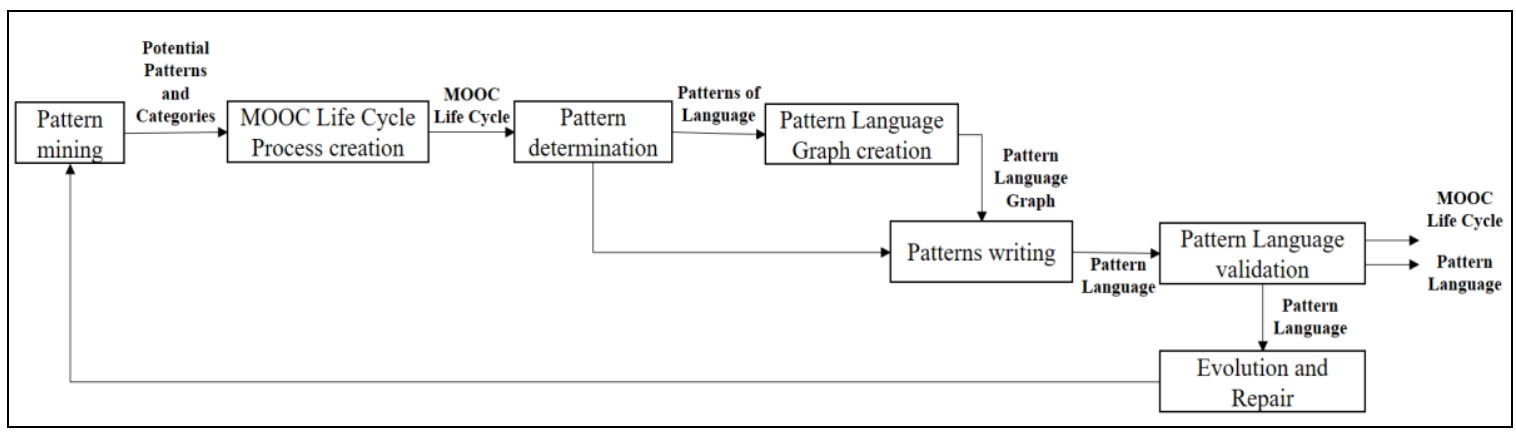

Figure 1 - The PL development. Adapted from Braga, Ré, and Masiero (2007).

\subsection{Pattern Mining}

According to Braga, Ré, and Masiero (2007), patterns are usually documented based on practice; to build a PL that covers applications in certain contexts is necessary to observe and collect solutions that are commonly employed to solve recurring problems in a domain. In this work, a collection of pattern candidates (or proto-patterns) to support the design for learning in MOOCs was firstly identified from four main sources as described below.

\section{Review of strategies to design and develop MOOCs}

As there are no well-known and established approaches regarding the design of MOOCs, in previous work we conducted a study (Fassbinder et al., 2017b) to identify best practice and discover embodied learning design patterns. The retrieved studies were grouped into: (i) specific instructional design models for MOOCs, such as the MOOC Design Model (Lee, 2016), the MOOC Canvas (Alario-Hoyos et al., 2014), and the MOOC Design Patterns Project (Warburton and Mor, 2015); (ii) traditional instructional design models applied in the context of MOOCs, such as the case of Croxton and Chow (2014), who used fundamentals based on the well-known ADDIE model (Molenda, 2003) as a framework for developing a MOOC to teach web design and usability; and 
(iii) general strategies that explored essential MOOC learning design characteristics, as presented in Spyropoulou, Pierrakeas, and Kameas (2014).

\section{Guidelines shared by MOOC Providers}

Patterns from MOOC providers' guidelines were verified using Software Engineering principles based on requirements gathered by analyzing various documents. Current guidelines available for educators and partners who want to deliver MOOCs using Coursera and MiríadaX were reviewed. Reviewing their best practices and design activities helped us to understand the current situation as well as identify the related vocabulary and the stakeholders involved in the MOOC development. We also used the partial results to formulate questions for a survey of MOOC practitioners.

\section{MOOC Guidelines from Universities/Institutions}

Guidelines for the development of MOOCs provided by universities/educational institutions were also considered. The procedure was the same as described above, but now it took into account documents created and shared by universities. The University of Glasgow ${ }^{1}$, for instance, provides a practical overview based on the design and implementation of the university's first two MOOCs.

\section{Survey of MOOC Practitioners}

In addition to reviewing literature and guidelines from MOOC providers and universities, we also carried out a survey where MOOC instructors were asked about their experiences designing MOOCs (Fassbinder et al., 2017b). An initial analysis of the survey data, considering 91 respondents around the world, revealed that: (i) almost $60 \%$ of instructors are novices in learning/instructional design fundamentals in general, not only in MOOCs; (ii) 85\% agree that using learning design models will probably result in better courses than ad hoc or random decisions about the MOOCs design; (iii) around 53\% use content-based approaches (i.e., video lectures, forum, automatic assessments) as the main pedagogical approach to design MOOCs; (iv) $85 \%$ do not use specific methods or frameworks to design MOOCs, only a mix of ad hoc decisions, institutional or MOOC providers' guidelines.

\subsection{MOOC Life Cycle Process creation}

The Pattern mining phase helped us to identify pattern candidates for future use. Their core elements were described as name, context, problem, and solution. They were also grouped into "families of patterns" that shared certain design goals. The groups represent key activities of a general MOOC Life Cycle Process (Fig. 2) that we established to summarize a set of design steps that can be applied systematically, with the aim to ensure a degree of quality in the design of MOOCs (Fassbinder et al., 2016).

The cycle is embodied in a set of actions informed by commonly linked and complementary theories from the perspective of learning design, education, and technology to support teaching and learning practices in MOOCs. Also, the main contribution of this MOOC Life Cycle Process is the use of Flipped Learning concepts as a pedagogical model to guide the MOOC team in the design for learning in MOOCs.

\footnotetext{
${ }^{1}$ http://www.gla.ac.uk/media/media_395337_en.pdf
} 


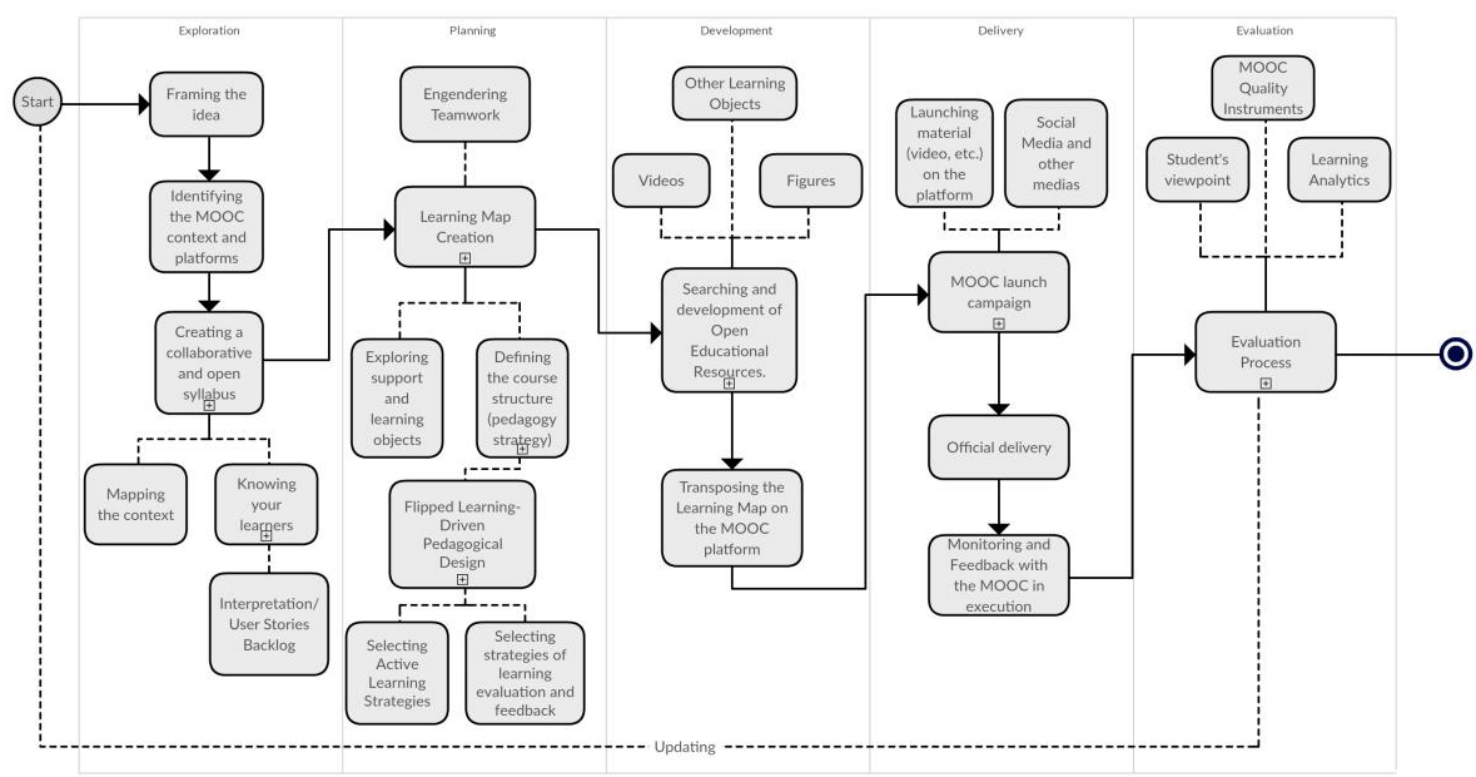

Figure 2 - A MOOC Life Cycle Process (Adapted from Fassbinder et al., 2016).

Flipped Learning (FL), also known as Flipped Classroom, is an educational strategy that has been applied in formal courses to enhance teaching and learning (Sams and Bergmann, 2013). Its primary definition is based on a simple re-organization of out and in-class learning activities, which could be indeed a possible strategy to apply it. In our previous studies (Fassbinder et al., 2016), we investigated how the FL teaching model could be incorporated into MOOC design to support the planning phase of the MOOC Life Cycle Process, acting as an intervention to enhance the current design for learning in MOOCs. This is because FL is based on several theories linked to learning and pedagogy, which can emphasize collaborative and self-regulated learning, and increase students' engagement. FL also offers an alternative way to orchestrate the use of active learning activities, such as Project-based Learning and Problem-based Learning. Besides, it represents a shift in the way of thinking open and online teaching/learning.

\subsection{Pattern determination}

The MOOC Life Cycle Process resulting from the previous phase was used to identify more patterns, refine the current ones, and guide the Pattern Language Graph creation. We also planned and delivered two MOOCs (Fassbinder et al., 2016; 2017a) to validate the already obtained patterns, find new ones, and improve their description.

\subsection{Pattern Language Graph creation}

In this phase, a graph was defined to show the interaction between the patterns or the patterns application flow. The related graph is described in Fig. 3.

\subsection{Patterns Writing}

Once the Pattern Language Graph was created, the additional field named "next patterns" was defined to support the flow definition in which the patterns are used or applied to design a MOOC. The final patterns format was also defined, considering a specific pattern language for pattern writing described by Meszaros and Doble (1997) and the format used by Iba (2014). Each pattern was described using the following standard form: Pattern Number, Pattern Name, One-liners to explain the pattern, Illustration, Context, Problem, Forces, Solution, and Actions. Examples and Related Patterns are cited when needed. 
VI Congresso Brasileiro de Informática na Educação (CBIE 2017)

Anais do XXVIII Simpósio Brasileiro de Informática na Educação (SBIE 2017)

\subsection{Pattern Language evaluation}

A mix of strategies was used to evaluate the MOOC Life Cycle Process and mainly the Pattern Language. The evaluation process is described in more detail in Section 5.

\subsection{Evolution and repair}

A web tool to support the management of the patterns and the PL itself is on development ${ }^{2}$. Its main purpose is to act as a way to support patterns dissemination, their improvement, and collaborative work between practitioners.

\section{Overview of the Educational Design Pattern Language for MOOCs}

The PL suits novices and experienced MOOC practitioners. Novices may choose to use learning patterns as suggestions to be tried and adopted, while experts can use them as a form of validation, helping them to incorporate in their designs some of the desirable characteristics for MOOCs. Fig. 3 presents the PL related graph.

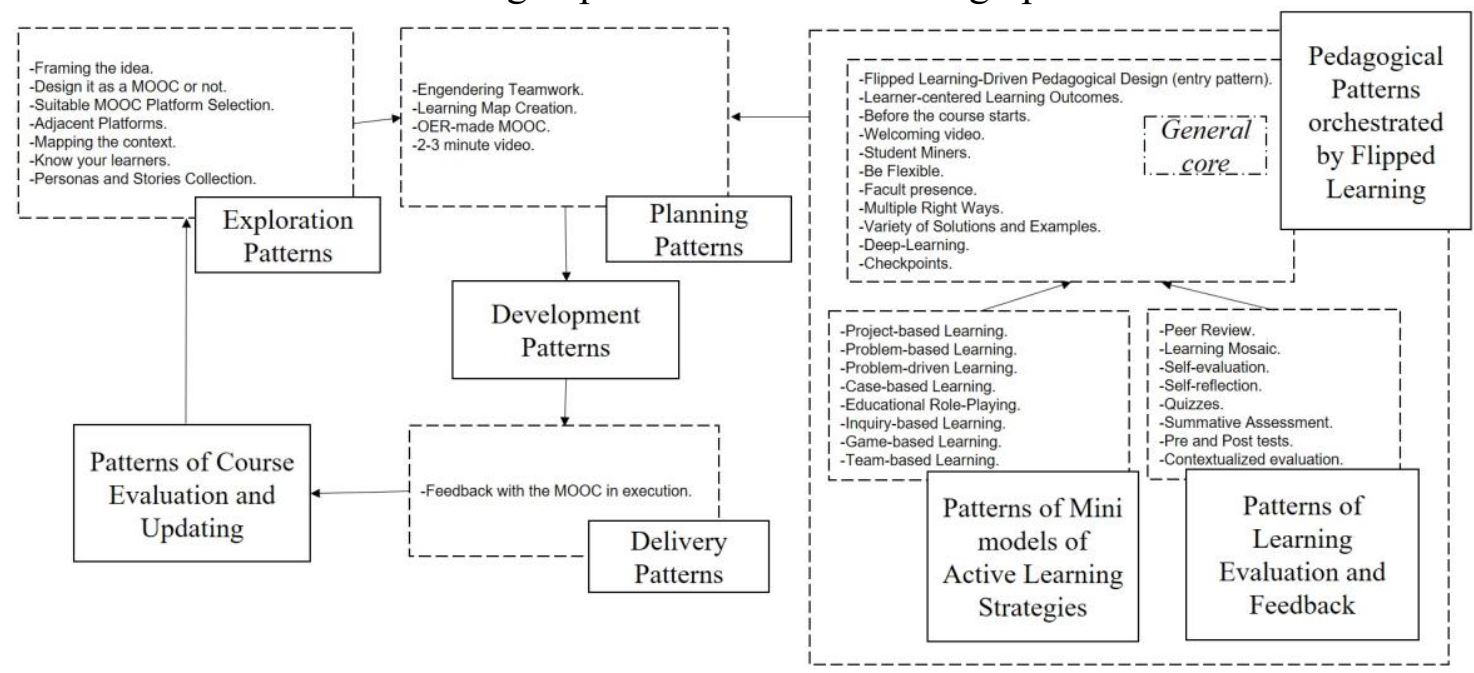

Figure 3 - Educational Design Pattern Language graph (Adapted from Fassbinder, Barbosa, and Magoulas, 2017).

The patterns are grouped into eight categories, as described next.

- Exploration patterns: this category starts the development cycle of a MOOC and contains patterns that enable MOOC teams to understand their needs, the university context, available resources, and the goals and needs of the target audience.

- Planning patterns: this category contains patterns describing how to create a Learning $\mathrm{Map}^{3}$ for MOOCs, how to use Flipped Learning ideas and principles as a pedagogical strategy to guide the development of the Learning Map, and what to consider when planning videos and other learning objects.

- Pedagogical Patterns orchestrated by Flipped Learning (general core): this category offers an entry point and more specific patterns to support the Planning phase based on Flipped Learning ideas and fundamentals.

- Patterns of Mini models of Active Learning Strategies: this category includes patterns that describe the application of active learning strategies adapted for MOOCs.

\footnotetext{
2 http://labsoft.muz.ifsuldeminas.edu.br/projetos/openedupatterns

3 A Learning Map usually contains course organization, a sequence of activities, and learning outcomes to be achieved by students undertaking the proposed course.
} 
VI Congresso Brasileiro de Informática na Educação (CBIE 2017)

Anais do XXVIII Simpósio Brasileiro de Informática na Educação (SBIE 2017)

- Patterns of Learning Evaluation and Feedback: this category contains patterns that capture different evaluation and feedback strategies that can be adapted to the MOOC context.

- Development patterns: this group contains more operational patterns, which support the implementation of the Learning Map into the chosen MOOC Platform.

- Delivery patterns: this group relates to the course offered on the chosen MOOC platform, as well as activities to monitor and give feedback to students.

- Patterns of Course Evaluation and Updating: this group includes patterns related to the MOOC evaluation during and after its offering. Also, includes patterns that refer to the analysis of findings from the MOOC summative evaluation and the identification of future improvements for new deliveries.

As an example, Fig. 4 presents a description of the pattern named FLIPPED Learning-Driven Pedagogical Design. The description of other patterns is available on the website (caed.icmc.usp.br/mooc).

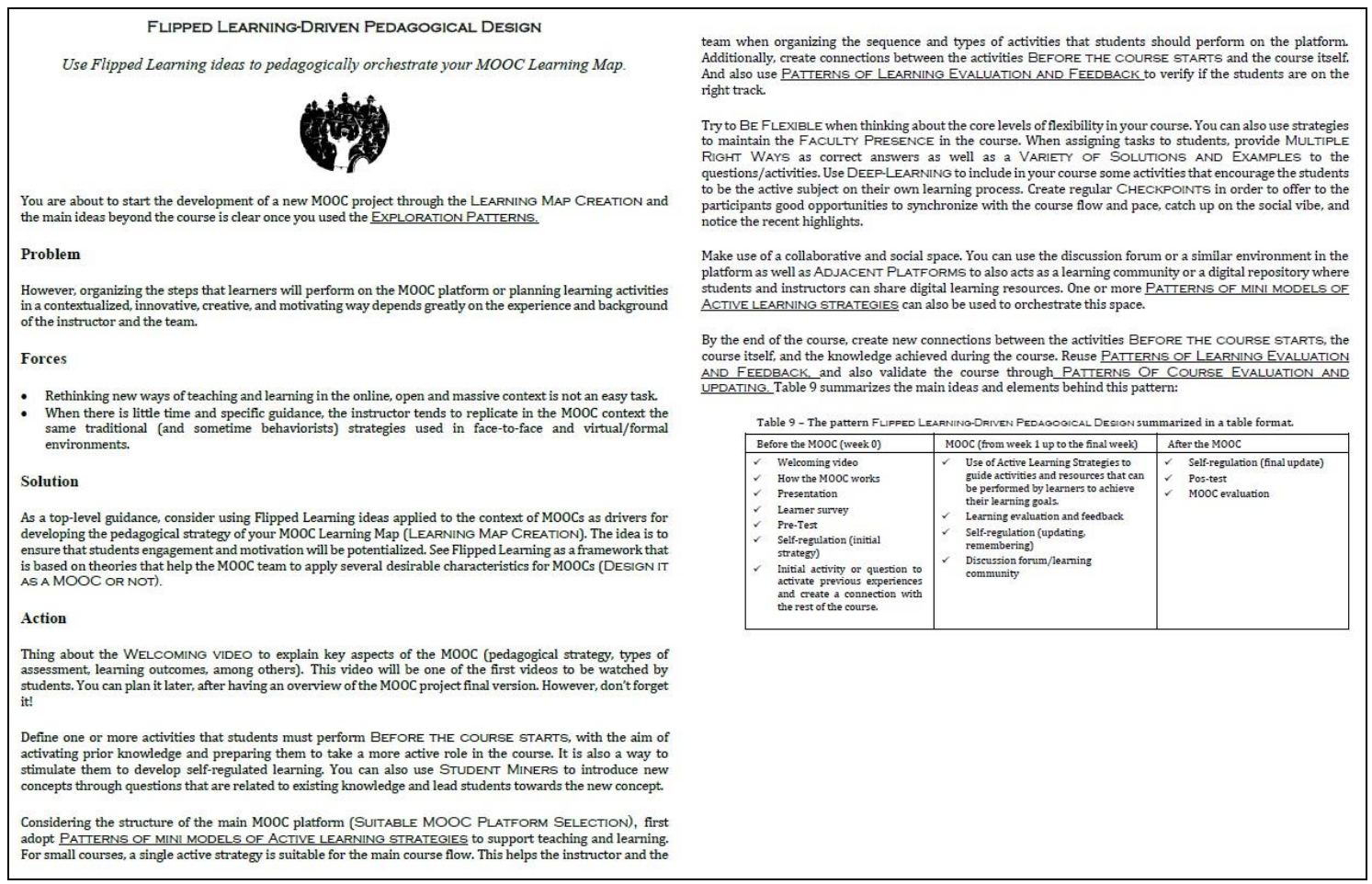

Figure 4 - An example of a pattern.

\section{Pattern Language instantiation: A Case Study on Agile Development}

In this section, the use of the PL is exemplified by a set of design steps performed to create a MOOC about Agile Software Development. It is worth noting that the sequence presented in Table 1 is not the only one possible since a PL is structured as a network and the relation between patterns can be captured through different ways, according to Alexander et al. (1977) and Iba (2014).

The proposed flow starts with more generic patterns and gradually applies those which are more specific. Due to space limitations, we only show the application of a small number of patterns belonging to the Exploration, Planning, and Pedagogical patterns categories.

Table 1 - A general approach for using the Pattern Language.

\begin{tabular}{|c|c|}
\hline Design steps/patterns & \multicolumn{1}{c|}{ Action based on the pattern solution field } \\
FRAMING THE IDEA & $\begin{array}{l}\text { The first step is always the most complicated when starting a new project. Thus, we started } \\
\text { planning the MOOC by considering personal, institutional, and technological aspects, which could }\end{array}$ \\
\hline
\end{tabular}


VI Congresso Brasileiro de Informática na Educação (CBIE 2017)

Anais do XXVIII Simpósio Brasileiro de Informática na Educação (SBIE 2017)

\begin{tabular}{|c|c|}
\hline & influence the MOOC design. \\
\hline $\begin{array}{c}\text { DESIGN IT AS A MOOC } \\
\text { OR NOT }\end{array}$ & $\begin{array}{l}\text { The MOOC team wanted to understand the desirable characteristics for a MOOC project, before } \\
\text { building one, but we did not know how to start. A synthesis of characteristics and aspects that must } \\
\text { be found in MOOC projects is listed in an instrument named "Artefact to support the validation of } \\
\text { MOOC projects". We used the instrument to help us. }\end{array}$ \\
\hline $\begin{array}{c}\text { SUITABLE MOOC } \\
\text { PLATFORM SELECTION }\end{array}$ & $\begin{array}{l}\text { We needed to choose a suitable platform to deliver the MOOC but also understand the key features } \\
\text { available in the software that could have an impact on the course design. Thus, we familiarized } \\
\text { ourselves with the MOOCs platforms available in our institution and the market. }\end{array}$ \\
\hline ADJACENT PLATFORMS & $\begin{array}{l}\text { The MOOC team wanted to make the course rich and diverse, but the platform was somewhat } \\
\text { limited in scope as it provided a common foundation for all courses. As enhanced functionalities } \\
\text { were required, we found additional tools and services to meet teaching and learning needs. }\end{array}$ \\
\hline MAPPING THE CONTEXT & $\begin{array}{l}\text { How can a MOOC team propose a different, innovative and catchy course for students if we do not } \\
\text { know the current state of MOOC production in our area? Thus, we tried to familiarize ourselves } \\
\text { with the relevant courses available on the top MOOCs platforms, compared the definitions already } \\
\text { made for our MOOC, and used the results obtained to refine our course design. }\end{array}$ \\
\hline KNOW YOUR LEARNERS & $\begin{array}{l}\text { Identifying personas (categories or groups of learners) of a MOOC and their respective interests, } \\
\text { needs and desires is always a challenge, due to several factors, such as the high number of people } \\
\text { involved or the diverse socio-economic-cultural and educational background of the audience. The } \\
\text { course should be designed with who in mind? Thus, first we created an initial sketch of the } \\
\text { personas to represent the MOOC' target audience. We planned flexible strategies to address such } \\
\text { groups and bring them good learning experiences. We used PERSONAS AND STORIES } \\
\text { COLLECTION to support us. }\end{array}$ \\
\hline $\begin{array}{c}\text { PERSONAS AND } \\
\text { STORIES COLLECTION }\end{array}$ & $\begin{array}{l}\text { It is difficult, expensive and hard work to do quantitative or qualitative research with a MOOC } \\
\text { target audience. Another question is: how to do it? A web questionnaire to support the pattern "As } \\
\text { (function, job title or user profile), I (should, want to, would like to) (action or goal), with the } \\
\text { purpose of (value for personal or professional life)" proved to be a good strategy. }\end{array}$ \\
\hline $\begin{array}{l}\text { LEARNING MAP } \\
\text { CREATION }\end{array}$ & $\begin{array}{l}\text { Transposing a course plan to a virtual platform is not an easy task. It is also difficult to define a } \\
\text { common written language that is easily understood by all team members. Thus, we managed and } \\
\text { consolidated the course planning through a concept named Learning Map (also called Activity } \\
\text { Map). The simple and visual nature of this concept forces the instructor to prepare clear, short, and } \\
\text { meaningful information. It is easy to complete and allows fast updates. It was necessary to use } \\
\text { FLIPPED LEARNING-DRIVEN PEDAGOGICAL DESIGN, among other patterns. }\end{array}$ \\
\hline $\begin{array}{l}\text { FLIPPED LEARNING- } \\
\text { DRIVEN PEDAGOGICAL } \\
\text { DESIGN } \\
\text { (example based on Fig. 4) }\end{array}$ & $\begin{array}{l}\text { With a Learning Map, a team can plan a course and visualize the expected learner's steps on the } \\
\text { MOOC platform. However, organizing these steps or activities in a contextualized, innovative, } \\
\text { creative and motivating way depends greatly on the experience and background of the instructor } \\
\text { and the team. Thus, as a top-level pedagogical strategy, we used Flipped Learning ideas applied to } \\
\text { the virtual, open, and massive context. Flipped Learning was considered as a framework based on } \\
\text { several theories that help the MOOC team to apply several characteristics required for MOOCs } \\
\text { (DESIGN IT AS A MOOC OR NOT) and PATTERNS OF MINI MODELS OF ACTIVE LEARNING } \\
\text { STRATEGIES. Main activities include: } \\
\text { Activities before the course starts: welcoming video, how the MOOC works, instructors' and } \\
\text { students' presentation through an interview-video strategy, learner survey, pretest, self-regulation } \\
\text { activity (defining goals and skills to be achieved by the final of the course), initial discussion } \\
\text { question to activate previous experiences about the course subject). } \\
\text { During the course: use of Project-Based Learning and Problem-Driven Forum as active learning } \\
\text { strategies to guide the rest of the course; self-regulation activity (updating, remembering); } \\
\text { discussion forum; remote pair programming activities, quizzes. } \\
\text { Final of the course: self-regulation (final update), pos-test, and course evaluation. }\end{array}$ \\
\hline
\end{tabular}

\section{Evaluation}

This section summarizes a mix of quantitative and qualitative methods used to validate the Educational Design Pattern Language proposed. According to Goodyear et al. (2004), development, evaluation, and dissemination of design patterns and pattern languages are collaborative activities, usually extending over several years. Besides, Braga, Ré, and Masiero (2007) highlight that a complete evaluation of a PL is a difficult task because many applications are required to guarantee its usefulness. Abraham (2008) also highlights that, despite the popularity of patterns, there is a lack of empirical studies evaluating when a shared understanding through patterns is valid.

To support the evaluation phase, Goodyear et al. (2004) and Braga, Ré, and Masiero (2007) suggest the use of online tools, such as wikis, and conferences, for example the Pattern Languages of Programs (PLoP), which undergo rigorous "shepherding strategies" before and during the face-to-face meeting. Abraham (2008) suggests the use of controlled studies with expert designers and users, and proposes the 
evaluation of a PL considering four criteria: cohesiveness, generativity, design guidance and coherence, using a pattern-sorting exercise.

The PL presented in this paper was evaluated through empirical studies and experts review as internal evaluation methods. A field evaluation with educators using the PL as a guide to develop their MOOCs was considered as an external evaluation method to confirm usability, satisfaction, trustworthiness, and educational effects. Both evaluations are shortly described next.

\section{Empirical study}

To empirically evaluate the PL and plan further research activities, we organized and performed a controlled study considering the ideas presented in Wohlin et al. (2012). Our main research goal was outlined using the Goal/Question/Metric (GQM) framework defined by van Solingen and Berghout (1999) and presented in Table 2. We also used specific questionnaires to investigate the level of satisfaction, confidence, ease of use, and intention of the subjects to use the PL to design MOOCs.

Table 2 - GQM of the empirical study.

\begin{tabular}{|l|l|l|}
\hline \multicolumn{1}{|c|}{ Goal } & \multicolumn{1}{|c|}{ Question } & \multicolumn{1}{c|}{ Metric } \\
\hline $\begin{array}{l}\text { To investigate the effect of } \\
\text { using the PL to design } \\
\text { MOOCs. }\end{array}$ & $\begin{array}{l}\text { Does the use of the PL } \\
\text { affect MOOC Project's } \\
\text { quality? }\end{array}$ & $\begin{array}{l}\text { Use of a rubric to evaluate two MOOC Learning Maps for } \\
\text { each subject/pair. The first one built using ad hoc approach. } \\
\text { The second one built using the PL. }\end{array}$ \\
\hline
\end{tabular}

In this evaluation, our main object of study was the MOOC Learning Maps built by teachers and students from Computer Science who had no knowledge of MOOCs development. The study was conducted in three different Brazilian universities, from September 2016 up to May 2017, following the same experimental design. Each application lasted four hours, and the subjects had the choice to work in pairs or individually. At the first two hours, they had to develop a MOOC Learning Map on an ad hoc basis. In the second part, the subjects had to create a new Learning Map about a different subject using our PL. A specific rubric to validate the MOOC Learning Maps was used to measure the effects of the methods (ad hoc versus pattern language) on the Learning Maps. There were 50 participants in this empirical study, randomly selected on a voluntary basis, and without getting any compensation.

\section{Experts' review}

PLoP conferences offer special reviewing process and support for authors who want to receive peer feedback on their patterns by fellow authors (the shepherds) with experience in pattern writing. Our PL and its patterns were refined under a shepherding process $^{4}$ in an International Conference on Pattern Language of Programs organized by the Hillside Design Patterns community ${ }^{5}$ (Fassbinder, Barbosa, and Magoulas, 2017).

\section{Field evaluation}

An external evaluation was carried out by fifteen volunteers not involved in the development of the PL. We used the same design of the experimental study, but human subjects (i.e., teachers, instructional designers) were allowed to perform normal learning design tasks (i.e., creating a Learning Map) from their natural places of work (i.e., at school or at home), wherever and whenever was more convenient to them. They used the PL to develop MOOC Learning Maps for their fields of activity, such as

\footnotetext{
${ }^{4}$ See http://hillside.net/the-language-of-shepherding for more details on the process.

${ }^{5} \mathrm{http} / /$ www.hillside.net/plop/2017/
} 
Programming Logic; History teaching; Cinema and cross themes; Inclusive Education; and Residential Electrical Installations. The variables used to evaluate this phase are the same described previously: effect (ad hoc versus pattern language), the level of satisfaction, confidence, ease of use, and intention of future use.

\section{Discussion}

The internal and external evaluation methods conducted have yielded interesting results and assisted us in improving the PL. The rubric used to evaluate the Leaning Maps in the field evaluation has a total of eight dimensions of desirable characteristics for MOOCs. Each dimension contains several related items. The subjects had to check to what extent their Maps contemplated such items. In Fig. 5, we focus on "Competency-

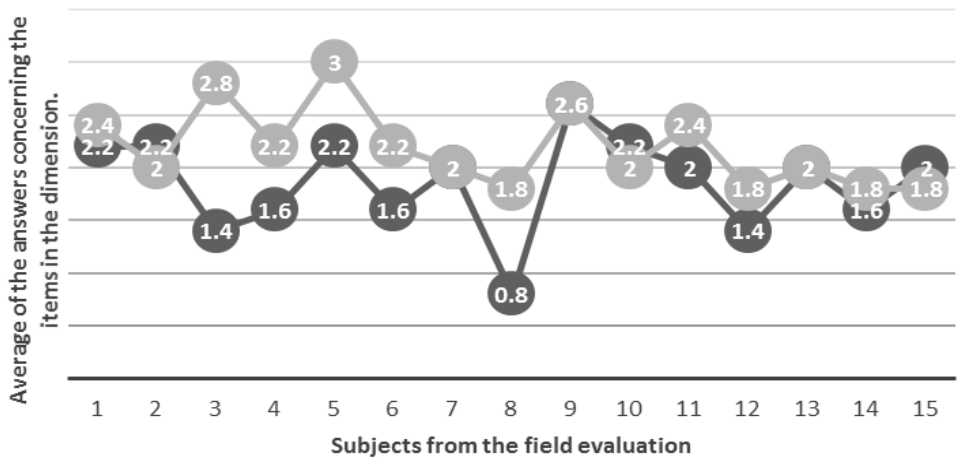

$\longrightarrow$ Competency-based design (ad hoc) $\quad$ Competency-based design (PL)

Figure 5-A sample of fifteen subjects and the average of their MOOC Learning Projects evaluation using ad hoc versus the Pattern Language. based design", which contains five items, and analyze the Learning Maps of fifteen subjects. The balls represent the average of answers concerning the five items of this dimension, for each subject, based on a four-point Likert Scale ([0] Not contemplated; [0.1 - 1.0] Partially contemplated; [1.1 - 2.0] Sufficiently contemplated; $[2.1-3.0]$ Totally contemplated). In general, the average of values belonging to Learning Maps developed with the PL support is higher than maps created using ad hoc approach. This trend was observed in other dimensions, such as "User-centered Learning" and "SelfRegulation Learning". Thus, there is evidence that Learning Maps developed using the PL contemplate more desired characteristics for MOOCs than those based on ad hoc or random decisions. We also have found good evidence on the use of the PL from empirical study considering the level of satisfaction, confidence when using the PL, ease of use, and the intention of future use, as summarized in Table 3.

Table 3 - Result from the evaluation questionnaire applied in the empirical study.

\begin{tabular}{|l|c|c|c|c|c|}
\hline & totally agree & agree & neither agree or disagree & disagree & totally disagree \\
\hline $\begin{array}{l}\text { High level of satisfaction when } \\
\text { using the PL. }\end{array}$ & $16 \%$ & $60 \%$ & $12 \%$ & $12 \%$ & - \\
\hline High level of Confidence. & $20 \%$ & $52 \%$ & $12 \%$ & $12 \%$ & $4 \%$ \\
\hline The PL is easy to use. & $20 \%$ & $44 \%$ & $16 \%$ & $8 \%$ & $12 \%$ \\
\hline Positive intention of future use. & $68 \%$ & - & $32 \%$ & - & - \\
\hline
\end{tabular}

\section{Conclusions and Future Work}

In this paper, we have discussed the research, development, and evaluation of an Educational Design Pattern language to support instructors when designing for learning in the context of Massive Open and Online Courses (MOOCs). The pattern language contains a total of thirty-nine patterns, grouped into eight categories. In addition, Flipped Learning ideas and fundamentals were used as a pedagogical support to guide the MOOC team in the development of Learning Maps and to orchestrate a set of activities that could be used to enhance learning experiences, increase students' engagement in the course, and emphasize self-directed learning. 
VI Congresso Brasileiro de Informática na Educação (CBIE 2017)

Anais do XXVIII Simpósio Brasileiro de Informática na Educação (SBIE 2017)

The paper has aimed to illustrate theoretical and practical aspects of development and validation of the pattern language and its usefulness for educators and learning designer practitioners. Furthermore, the proposed language offers guidance to educational technologists who are developing or adapting MOOC platforms to support self-regulated learning and active learning approaches, such as Project-based Learning, Problem-based Learning, Role-playing, among others.

The analysis of the preliminary results from the internal and external evaluation methods has indicated that the Educational Design Pattern Language can be effectively applied to guide the entire process of MOOC design. However, we highlight the need for investigating further its application in different contexts, not only in Software Engineering Education. The proposed pattern language is part of an Instructional Framework for MOOCs that we have worked on. The framework also contains artifacts and digital tools to support the main activities of the cycle of MOOCs development.

\section{Acknowledgement}

The authors are grateful to the Brazilian funding agencies (FAPESP, CAPES, and CNPq) and the IFSULDEMINAS for their financial support.

\section{References}

Abraham, G. (2008) "Evaluating a Pattern Language as Shared Language for Interaction Design", HCI Consortium. Available at http://www.pages.drexel.edu/ sga72/docs/sharedLanguage.pdf

Alario-Hoyos, C., Pérez-Sanagustín, M., Cormier, D. and Kloos C. D. (2014) "Proposal for a Conceptual Framework for Educators to Describe and Design MOOCs." J. UCS 20, no. 1, pp. 6-23.

Alexander, C., Ishikava, S., Silverstein, M. “A Pattern Language”. Oxford University Press, 1977.

Braga, R. T. V., Ré, R. and Masiero, P. C. (2007) “A Process to Create Analysis Pattern Languages for Specific Domains”, In: Proceedings of SugarLoafPLoP, 2007.

Croxton, R. A. and Chow, A. (2014) "Using ADDIE and Systems Thinking as the Framework for Developing a MOOC: A Case Study", In: 37th Practice of Educational Communications and Technology, Florida.

Fassbinder, A. G. O., Delamaro, M. E. and Barbosa, E. F. (2014). Construção e Uso de MOOCs: Uma Revisão Sistemática. Simpósio Brasileiro de Informática na Educação-SBIE, Vol. 25, pp. 332.

Fassbinder, A. G. O.; Fassbinder, M.; Barbosa, E. F., and Magoulas, G. (2016) "Towards a MOOC Design Model based on Flipped Learning and Patterns: A Case on Introductory Courses". In: XXI Congresso Int. de Tec. Educativa (TISE), Santiago, Chile.

Fassbinder, A. G. O., Barbosa, E. F. and Magoulas, G. D. (2017) “Towards an Educational Design Pattern Language for Massive Open Online Courses (MOOCs)", $24^{\text {th }}$ Conference on Pattern Languages of Programs (PLoP), Vancouver, Canada.

Fassbinder, A. G. O., Fassbinder, M., Barbosa, E. F. and Magoulas, G. D. (2017a) "Massive Open Online Courses in Software Engineering Education", In: Frontiers in Education, Indianapolis, United States.

Fassbinder, A. G. O et al. (2017b). Strategies to design for learning in MOOCs. (Manuscript in preparation)

Gamma, E., R. Helm, R. Johnson, and J. Vlissides. (1995) "Design Patterns: Elements of Reusable Object-Oriented Software".

Goodyear, P., Avgeriou, P., Baggetun, R., Bartoluzzi, S., Retalis, S., Ronteltap, F. and Rusman, R. (2004) “Towards a pattern language for networked learning", Networked Learning Conference, pp. 449-455.

Iba, T. (2014) "Learning Patterns: A Pattern Language for Creative Learning (Pattern Language 3.0 Catalogue), CreativeShift Lab.

Iba, T., Sakamoto, M. and Miyake, T. (2011) "How to write tacit knowledge as a Pattern Language: Media Design for spontaneous and collaborative communities", Social and Behavioral Sciences 26, pp. 46-54.

Lee, G. et al. (2016) “A study on the development of a MOOC design model”, Educational Technology International, v. $17, \mathrm{n} .1$.

Meszaros, G. and Doble, J. (1997) “A Pattern Language for Pattern Writing”, In. International Conference on Pattern languages of program design, Vol. 131.

Molenda, M. (2003) "In search of the elusive ADDIE model”, Performance improvement, v. 42, n. 5, pp.34-37.

Sams, A.; Bergmann, J. (2013) "Flip your students' learning. Educational leadership", v.70, n.6, pp.16-20.

Siemens, G. (2013) "Massive open online courses: Innovation in education”, Open educational resources: Innovation, research and practice, v. 5, pp. 5-15.

Spyropoulou, N., Pierrakeas, C. and Kameas, A. (2014) "Creating MOOC Guidelines based on best practices.", In: EDULEARN14, pp. 6981-6990.

van Solingen, R., Berghout, E. (1999) "The Goal/Question/Metric Method: A Practical Guide for Quality Improvement and Software Development”, McGraw-Hill International, London/Chicago.

Warburton, S. and Mor, Y. (2015) “A set of patterns for the structured design of MOOCs", Open Learning: The Journal of Open, Distance and e-Learning, pp. 1-15.

Wohlin, C., Runeson, P., Höst, M., Ohlsson, M. C., Regnell, B. and Wesslén, A. (2012) "Experimentation in software engineering”, Springer Science \& Business Media. 